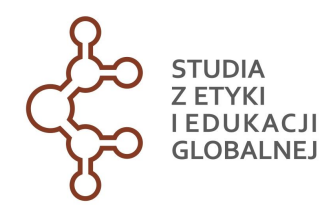

nr 1/2014, ss. 117-135

MIROSLAW FILICIAK

Szkoła Wyższa Psychologii Społecznej

PIOTR TOCZYSKI

Akademia Pedagogiki Specjalnej

\title{
Peer Re-Production and an Extended Culture Industry. The Case of TV Content and Redistribution in Europeanizing and Globalizing Poland
}

\begin{abstract}
Television content - mostly American productions - circulates among Polish Internet users. The article analyzes the increase in the scale of re-production of audiovisual content among large groups of the Polish network society. The growth in "peer re-production" constitutes an "extended culture industry." The case of Poland is studied with quantitative audience research and survey research. The growth in the use of streaming websites providing free access to audiovisual content is explained in terms of the Polish local history of "piracy," ongoing global processes and the generation gap.
\end{abstract}

Key words: extended culture industry, globalizing Poland Internet, media redistribution, media piracy, TV content

\section{INTRODUCTION}

In this article, we focus on the global phenomenon usually called "piracy," although we try to avoid this term, replacing it with more neutral ones. The phenomenon we analyze is the informal circulation of audiovisual content in contemporary Poland. American television series are the object of "peer re-production" that constitutes an "extended culture industry." We illustrate both these categories with the most appropriate data available from several sources, including computer-assisted web interviews we conducted. Although we refer the above to quite general issues such as "piracy" and "content," we redefine them before presenting research results as 
parts of the two key categories of the article, namely "peer re-production" and an "extended culture industry."

The problem of free access to professionally produced content circulating around the globe is not unique to globalizing and Europeanizing Poland. In the already existing literature, we find other examples of such flow from central to semi-peripheral and peripheral countries. Intending to present the flow and circulation of content as both global and local processes, we provide relevant references in the first part of the article. Firstly, in low-income countries, media goods, which we see as "pieces of content," are highly desired and highly priced, but freely available through "pirate" channels. Secondly, the cultural content exchange is integrated into everyday social and befriending practices, but into professional networks as well. "Pirate" networks intersect all dimensions of contemporary culture, including the academic community, and thus represent a generation gap only to a certain extent. This leads us to see who the actors of "piracy" are, both in terms of global settings, the historical trajectory and age groups. Following the issue of who is involved in "piracy," we focus on time and space of this phenomenon. The questions arise: In what ways is it global and what is its timeline in Poland? We respond to these questions with the historical method and then with data illustrating the growing number of "real users" of video streaming websites as well as other data, including survey research among Polish Internet users.

\section{Media Goods: Pieces of Content Available in the Networks}

The authors of the "Media Piracy in Emerging Economies" report, edited by Joe Karaganis (2011a), decided to use an unusual strategy, i.e. to release it under the terms of a Consumer's Dilemma license. It is based on diversifying access granted to persons from different parts of the world. People in countries classified as low-income countries pay nothing, but those who download the report in the U.S. and Western Europe need to pay $\$ 8$ or $€ 8$ for it. For commercial use, one has to pay $\$ 2,000$.

Or maybe they do not have to? "If you are residing in one of the listed high-income countries, want to read the report, but think that $\$ 8$ is an unreasonable price, you can acquire it for free through other means. In fact, we have made it exceedingly easy to do so. If you fall under the terms of the commercial reader license but think that $\$ 2000$ is unreasonable, you have the same options (plus the $\$ 8$ option). In both cases, the reader is faced with a dilemma: pay the legal price (roughly mapping ability to pay to a determination about whether the price is fair), acquire it through pirate channels, or don't bother with it. In most of the countries we've studied in this report, the results of this calculation with respect to DVDs, music, and software are strikingly 
consistent. Media goods are highly desired, exorbitantly priced with respect to local incomes, and freely available through pirate channels" - Karaganis (2011b) wrote in the blog accompanying the report.

As it can be seen, the report not only provides knowledge on developing countries, but it also allows residents of affluent countries experience dilemmas similar to people who are the subject of the report. This whole situation touches on yet another problem. It shows that "piracy" is not only a culture emerging around music and movies. Some researchers downloaded the report as "pirates" would do.

As the residents of Poland, we had the chance to download it legally and for free, but while working on this article, we often found ourselves in a situation where interesting and potentially useful texts across which we came were available in online databases for the access to which we had to pay (perhaps in contrast to our foreign colleagues, often benefiting from subscriptions purchased by their universities). However, the same articles could be "googled" in other places and read without paying. We mention this to show that "piracy" is not only the networks created by professional copy-traders or teens wanting to listen to their favorite band's album for free. This is not just a web equivalent to old youth subcultures, although accessing media content and sharing it is very important among youth and sometimes leads them to ethical dilemmas (Filiciak et al. 2013: 132, 176). It is more than that. Pirate networks intersect all dimensions of contemporary culture - also the academic community. Moreover, they are not limited to the conflict between Internet users and business, because the "pirate" activity that boosts the number of viewers remains "unnoticed" by many websites, as evidenced by the controversy surrounding sites such as YouTube, where audiovisual materials are often posted without the rightholders' consent. Thus researchers as well as big companies might be "pirates," which shows how fluid and ambiguous are the borders imagined for legal and illegal activities associated with copying and exchanging content.

Our knowledge of the mechanisms of "piracy" is still limited. One of these mechanisms is "engagement" that is becoming a new aim of ad-supported online businesses. Companies in the sector of culture often treat their customers as free workers nowadays (Terranova 2000). Cultural products are to be "spreadable," are to circulate in social networks and reach out to niches through redistribution carried out by enthusiasts, heavy and active users of online content. Yet the Internet was not designed as a tool for media distribution, but as possibly the most effective communication tool. The other side of this intended "spreadability" (Jenkins et al. 2010) is therefore the distribution of content beyond the control of producers and broadcasters 
(Filiciak et al. 2012, Toczyski 2012). As we will show, this is ubiquitous in Poland but popular in other parts of the world as well (Roettgers 2011).

The most significant change has thus taken place in an area which is researched to an incomparably lesser extent than content creation. This area is not production but the reproduction of content - especially the content that is produced by professionals, and then circulates on the Internet. The scale of its use is much higher than the increase in creativity caused by the popularity of the Internet. The consequences are great, too - both in terms of facilitating access to cultural content (mainly music, movies, television series and books), but also at the level of integration of the cultural content exchange with everyday social and friendly practices (cultural content in the form of a file becomes an element of exchange in social networks), and finally at the economic level, undermining the existing models of media industries.

The proper perspective to understand this reality seems to be the perspective of a "piece of content," a single content item. Content - a text, an image or an audiovisual recording - flows through the nodes of the network, subject to conversion to cultural and intellectual capital, social capital (understood as the strengthening of relations), and usually also economic capital - by saving money of those who decide to consume a "piece of content" for free. Content circulation is an important, non-judgmental concept. Regardless of the "medium," what remains essential is "content" (appreciated with such statements as "content is king", widely used in business). Thus the subject of "piracy" in terms of a "piece of content" is that the "medium" is skipped and that the circulation of "content" starts out of the loop provided by the publisher.

By adopting the perspective outlined above, we consider research on the informal economy of the media as an important and still poorly examined aspect of the sociocultural change. This change has taken place through the dissemination of digital and networked media, allowing almost any entity with access to the Internet to copy and distribute cultural content at almost no cost. At the same time, the entity is perhaps more the beneficiary than the driving force behind this change - because even though the Internet file-sharing networks of Internet users' individual computers play the role of major hubs, file-sharing often happens without any clear intention and often without the users being aware of it. Sometimes redistribution happens to be the "side effect" of the Internet's architecture, and more exactly the peer-to-peer networks' architecture, and default software settings for sharing (not downloading or uploading) files.

\section{The TIMe, SPACE AND ACTORS OF "PIRACY": AN EXTENDED Culture INDUSTRY?}

We refer here to "pirate" activities of Internet users rather than organized criminal trafficking. For ordinary citizens, "piracy" is an opportunity to facilitate contact with the content of culture, 
which not only happens at no cost, but is often the easiest in terms of convenience and user experience (Toczyski 2012). In this article, we will not pass judgments, because we are interested in the observed social practices and their technology and business conditions. The legal dimension of the phenomena being analyzed is interesting so far as breaking the law can be regarded as an illustration of the weak influence of arbitrary rules for controlling the flow of content in the social space. So instead of trying to explain or denounce "pirate" actions, valuating will mainly concern us so far as these actions are an example of tensions at the level of discourse. Even the term "piracy," which is sometimes used in respect of file-sharing networks, is ambiguous - as John Logie (2006) convinces, the meaning of this word was shaped in an era when copying and redistribution of original content was primarily an organized profit-oriented practice. Today, files are usually downloaded through "user-generated content" - though the word "generated" sounds ironically here - i.e. without the participation of brokers and money (unless one counts sites like once-famous PirateBay or even more famous Megavideo and the advertisements published by them).

In the context of these considerations, the question of the "ad-supported" model in combination with "piracy" comes up. Is avoiding advertisements, for example with ad-block, an act of piracy? Is not this action (bypassing advertisements) the core of the concept of movies and TV series "piracy?" "Piracy" certainly does not refer solely to the issue of copy-selling focused on micropayments (other ways of charging for content are used on a marginal scale). In the search for a business model that constructively resolves the "conflict of interests" between the content publisher and the consumer, one cannot ignore the development of the advertising market, advertising tools and attitudes to online advertising. These issues are merely indicated here, but they are worth extending on another occasion.

Discussions on the creative industries focus on large cities and industrialized countries, and yet new models are often developed elsewhere. In his analysis dedicated to the phenomenon of Nollywood, the Nigerian film industry, Ramon Lobato says: "Various efficient and economically sustainable industry models already exist in second and third world media (...). While creative industries policy seeks to formalize these economies, incorporating them into established networks of international trade, this is not the only possible response. It may well be that policymakers in the West can learn as much from developing nations about creative industries as 'they' can from 'us'" (Lobato 2010). Of course, it is not just about reversing the direction of influence. Perhaps what Nollywood producers dream about is to function as a Hollywood movie studio. But in the world where the Internet shook the traditional centralized model of media production and distribution, it is also likely that U.S. companies will have to 
borrow solutions from their counterparts operating in Nigeria, where the law is helpless against piracy. A glance at the statistics on the level of piracy in industrialized countries indicates that despite the intense efforts ongoing for over a decade, aimed at reducing the scale of file sharing on the Internet, the effects of these activities are as minimal as in Nigeria.

Moreover, the example of the third world shows that the boundaries between "pirate cultures" and the legitimate media market are blurred in many places around the world - the divisions imposed by the law often do not designate the boundaries of real circulation. Brian Larkin, who deals with piracy in Nigeria, notes that: "Nearly all of those who might be described as pirates were at the same time involved in the duplication and sale of legitimate media" (2004: 295). The situation was the same in Poland during the sociopolitical system transformation after the Polish People's Republic, when some companies entered the official distribution market, growing from small pirate initiatives and going through a transition period where the offer consisted of two available products: originals and copies.

Our article is devoted to the Polish case not only because we live here and are most aware of the situation here. Poland was the center of the unprecedented and successful youth citizen protests against the unconsulted anti-piracy law ACTA in 2012, which were in part motivated economically (Kuczyński 2014: 54). Although in other countries, "in real-life choices, youngsters may appear to be less ethical and law abiding, but the driving force behind this is mainly economical" (Weijters et al. 2013) just like in Poland, it was the Polish youth that stood against the new unwanted law, becoming an avant-garde for other European youngsters.

This shows that free access to media goods turned out to be important to an extent that was not foreseen before. Our case study is thus also motivated by the fact that Poland is situated - not only geographically but also politically - between the East and the West as an area subject to the Europeanization of the state and law and the Americanization of culture (the latter being, moreover, in our view, only a medium based largely on European content - sometimes mythical content and of distant origin - cf. Toczyski 2013). The perspective of Europeanization becomes especially valuable when we realize that since 2004, Poland has been the European Union member state. Intending to respond to the demands placed on the EU candidates, from the fall of the socialist People's Republic in 1989 to EU accession, Poland introduced changes to its legislation, which made the Polish system coherent with the copyright policy of its Western neighbors.

At the same time, however, at the level of everyday practice, informal exchange of cultural content is widely accepted in Poland. In principle, there has been no generation in Poland - at least since the 1970s - for which informal access would not be the primary form of 
access. "Pirate" media economics were legitimized by the practices of citizens seeking access to content which could not be obtained in a legal way. Since the 1980s these practices have been increasingly allowed and even stimulated by the flagging state and after the fall of the socialist People's Republic - by the Internet, in which, as Lawrence Lessig wrote, "it is code, rather than law, that rules" (2004: 148). The historical aspect seems to be important here - which does not mean that history is treated as the main explanation of the development of "piracy" in Poland. It rather adds a time dimension to the spatial dimension in the changing center-periphery relations, about which George Yudica, analyzing the example of Latin America, wrote that "the flows of influence no longer travel from center to periphery but circulate in multidirectional way among global cities through the world, much like the transactions of transnational corporations" (2003: 239). These flows also fluctuate over time - sometimes suddenly re-legitimizing what was stigmatized as obsolete or even barbaric until recently.

The element of time superimposed on the spatial heterogeneity has yet another dimension as it refers to generational conflicts of interest. Businesses located in Far East - as partly showed the example of the already closed Megavideo website, which operated, inter alia, (or perhaps mainly) from China, using a Chinese address - have no interest in respecting the “intellectual property rights" as possibly no sufficient volume of such competitive property exists in that region. Intellectual capital still belongs rather to the West. Even in the West, however, violations of intellectual property rights are sometimes a manifestation of social conflict that is a "generation gap" in this case as was suggested by Ivan Krastev in an interview conducted by Jacek Żakowski (2011). Krastev's interesting long-term perspective suggests that the West will depend on the protection of these rights because we are entering a "dictatorship" of older people, whose economic prosperity in the macro-scale depends on the implementation of intellectual property rights to a larger extent than the economic prosperity of young people. That would situate our subject in the category of the conflict of generations, a generation gap: as young people do not have the resources to get access to culture, because they are poor compared to the older generation, they want to access cultural content for free. The elders do not want to give them this access for free, hoping for royalties to secure themselves prosperous lives. And yet, thinking long term, access to culture is part of equal opportunities in life. Therefore, it would also be in the wider interest of the elderly to provide young people with the widest possible access to the content they search (ergo: those royalties should be somehow indirectly funded to authors or authors could even accept the loss of their royalties).

All the above seems coherent with the proposed title of our article, first created by Mirko Tobias Schaefer, who in the text Participation Inside? User Activities Between Design and Appropriation 
points out that it is difficult to change the media landscape seen only in the context of the increasing autonomy of audiences and the flowering of grass-roots creativity. This is because - as already mentioned - the persons intentionally creating culture texts constitute the margin of digital media users. What is archived on websites is often the "side effect" of communication processes.

In addition to creativity, Schaefer sees the creating and processing of content as an important area of the contemporary cultural landscape, as well as archiving, which is of interest to us here and which "refers to the organization, maintenance and distribution of the digital artifacts" (2009: 149). This area includes both legal resources and pirate activities. "Instead of replacing them, these new modes complement older modes of production, distribution, and consumption, and can therefore be described as establishing an extended culture industry. The extended culture industries are characterized by the dynamic interaction of all participating parties. Production processes are not only extended into the domain of users - where the (old) culture industry's media texts and products are appropriated - but also happen completely independent of established production and distribution channels. In conclusion, we can state that this present culture is constituted by new design and appropriation of existing content, unfolding along the lines of accumulation, construction, and archiving from the culture industries to its fringes and beyond" (Schaefer 2009: 150).

This way of conceptualization allows us to blur the artificial divisions between senders and recipients, whether professionals or amateurs. The relationships of individual actors are complex and "parasitic" relationships occur not only in the use of lawful products by Internet users, but also in the use of Internet users' activities by companies. Sometimes all of these aspects are present even within a single process, which is shown, for instance, by the epidemic of the "controlled leakage" of new episodes of television series to the Internet, which is now almost a standard marketing practice before the premieres of new seasons. It is, therefore, impossible to reduce these relationships to the question: "Who abuses who?" - as both Internet users (ab)use producers, accessing free material, and producers (ab)use Internet users, gaining a powerful marketing support in the network basically at no cost. Thus Schaefer's concept expands the thinking about "cultural participation" and "participatory culture", rightly pointing out that the roles of users and commercial entities are flexible and interchangeable, and commercial producers also participate in culture. "Participation cannot be assigned only to users who get involved with media and 'oppose' a dominant vendor. The original producer and other commercial units - who are either actively involved in the process of modifying the original design or benefit from its outcome - are also part of participatory culture” (Schaefer 2009: 153). 
Given the above, one more starting point for us might be the concept of peer reproduction. Yochai Benkler describes commons-based peer production as "radically decentralized, collaborative, and nonproprietary; based on sharing resources and outputs among widely distributed, loosely connected individuals who cooperate with each other without relying on either market signals or managerial commands" (2006: 60). Peer re-production works in a similar manner: anonymous Internet users share their resources (disc space, network connections, stored files), exchanging them in a non-hierarchical and out-of-the-market mode.

\section{Research Results 1. Alternative Circulation of Content in Poland - The Case OF TELEVISION}

To analyze the "extended culture industry" and "peer re-production" of contemporary media in Poland, we will focus on the content of television, mainly on American television series viewed on the Internet and via the Internet.

There are several reasons for such a choice. Firstly, it seems that the television industry, based on a business model that is different than in the case of the music and film industries, is more open to "domesticating" "piracy". Secondly, series in TV networks show internal contradictions of the extended culture industry. Although they potentially bring losses to producers, they potentially generate the revenue of other companies in the "ecosystem" that are sometimes associated with the traditional media business (a website named Popcorner could be found in the online portfolio of Agora, publisher of the quality print daily Gazeta Wyborcza; it focused on TV series and information about new productions, many of which were unavailable in lawful circulation in Poland when the website existed).

The TV series case is also interesting because it shows how pieces of content circulate among the media (understood not only as technology platforms, but also as reception practices: a series' episodes are often viewed differently on television than the same content downloaded from the Web). Over time, much of the "pirated" content is broadcasted on Polish TV stations. However, as it turns out, waiting several months for legal free access is unacceptable for many Internet users.

We have chosen this example also because it allegedly generates up to half of the traffic on $\mathrm{p} 2 \mathrm{p}$ networks (see the anecdotal evidence - Ernesto 2008) and there are certain groups in Polish society (especially big-city, educated youth) for whom foreign TV series are part of a certain fashion. Interestingly, TV series are watched by young people who do not have any television sets and antennas to receive television signals and who declare that: "All that could be interesting for me on TV, I find on the Internet" (Filiciak et al. 2013). 
Finally, this example shows the non-obvious connection between the global and the Polish circulation of the media. In this case, Polish Internet users - in many different ways which are discussed later on - become the audience of American television stations. These stations belong, however, to the era of post-network television, where the traditional channels of distribution have been fragmented to many alternative forms, ranging from thematic television channels, through the sale of television content on DVDs and online, to informal circulation, associated especially with the development of p2p networks and "pirated" streaming services, which will be the subject of further analysis.

Post-network television is still, in fact, the era of "network television," but the meaning of the word "network" has changed, relating today primarily to the Internet, which is becoming a basic interface to access television content for many people, especially the youth. These changes, moreover, are being converted into new business models - although the end of centralized broadcasting limited by the state borders is a problem for television stations, it also creates new opportunities to reach new audiences, such as the global middle class (which is the basic audience of American cable networks producing series circulating on the Internet). The organizations owning the rights to content are not the only ones that benefit from these opportunities - as exemplified by the IiTV.info website career in 2010 , the year significant also because of famous Megavideo's prosperity.

In principal, the IiTV.info website offers to Poles what Hulu.com offers to Americans with the difference that Hulu.com does it legally, because it has developed a proper business model (ad-supported video on demand), has the rights to content and publishes advertisements. Even at the time of this article going to print, there are hardly any legitimate counterparts of Hulu.com in Poland, although websites offering content broadcasted by individual television stations already function here. The local Polish start-up IiTV.info had no rights to content and in 2010, it was almost exclusively a "cover" for Megavideo, a global "pirate" site, which allegedly operated from Hong Kong, where the Western standards of intellectual property protection did not have to be used (due to the lack of academic sources on Megavideo, see http://en.wikipedia.org/wiki/Megavideo).

In Europe, Megavideo was popular particularly in Italy, which will be shown later on based on somewhat anecdotal data. The activity of IiTV.info is well illustrated by the recent Boardwalk Empire series (Polish premiere in 2011). In Poland, it was aired on pay TV a few months after the U.S. release, but all the episodes had been available through Megavideo by that time. In principle, audiovisual market producers do care about their products popularity, but they do not turn a blind eye to "pirate" practices. In the TV series segment, "publishers" are less 
effective: when Polish distributors were advertising Boardwalk Empire in a spectacular multimedia advertising campaign, the links to all the episodes had already been available on the IiTV.info site (stored on Megavideo and similar hosting and streaming websites). Moreover, these episodes had already been there before the Polish television began to create demand for the series. Thus the selection of the IiTV.info example for the needs of this article is not random, but dictated by its proximity to global Megavideo, allegedly operating from a non-Western location at that time.

To see website performance in the Polish population, it is justified to begin by asking what is said about IiTV.info in the results of Polish Internet audience research, widely accepted by the interactive industry (always focused on website audience figures). It should be remembered that the commercial standard of website audience measurement is funded by publishers, which have interest in maintaining the "ad-supported" model challenged by "piracy". The commercial standard, despite the discussion which ensued in the Polish media industry in 2010 and which was followed by the consultation process in the joint industry committee, is accepted by all the participants of the Internet advertising market and is not rejected by scholars from outside of the commercial Internet circles - though its potential is not fully used by Polish academics. Therefore, we are in favor of the opinion that even with inevitable errors this largely automated measurement causes, the Megapanel PBI/Gemius research is an authoritative source of knowledge about the websites and preferences of Polish Internet users ("Polish" in the sense of connecting to the network from the Polish territory and performing at least one "page view" per month from the Polish territory). Files with the results can be downloaded from http://gemius.pl/pl/login megapanel.

What are then the figures concerning the IiTV.info website in comparison with other sites? According to Megapanel, Polish Internet users generally watch the content of undefined rightholders or the content where the issue of property rights is not mentioned. Figure 1 shows a graph of website traffic dynamics of four sites in 2010 on a monthly basis. It shows an increase in the number of users (named "real users" in this methodology) of websites providing access to files, some of which are presented mainly as streaming, and some in the form of links to files for download. The number of IiTV.info users amounted to hundreds of thousands of "real users" over the year 2010. And the number of Megavideo.com users is several times greater than the number of IiTV.info users according to the graph. It is clear that the model presented by Torrenty.org (provides torrent files - metadata for $\mathrm{p} 2 \mathrm{p}$ networks) and Speedyshare.com (makes it possible to upload and download large files) is maintained at a stable level, or even leads to declines in the scale of the results of 12 months. The number of users of files available for streaming through IiTV.info and Megavideo.com is growing. IiTV.info is a specialized website 
that contains only links to foreign TV series, often unavailable on Polish television, which are located primarily on Megavideo, often without resolving the issue of the rights to the content.

Figure 1. Number of "real users" of websites with the content of undefined rightholders or the content presented without addressing the issue of property rights in 2010. Source: Megapanel PBI/Gemius, 2010

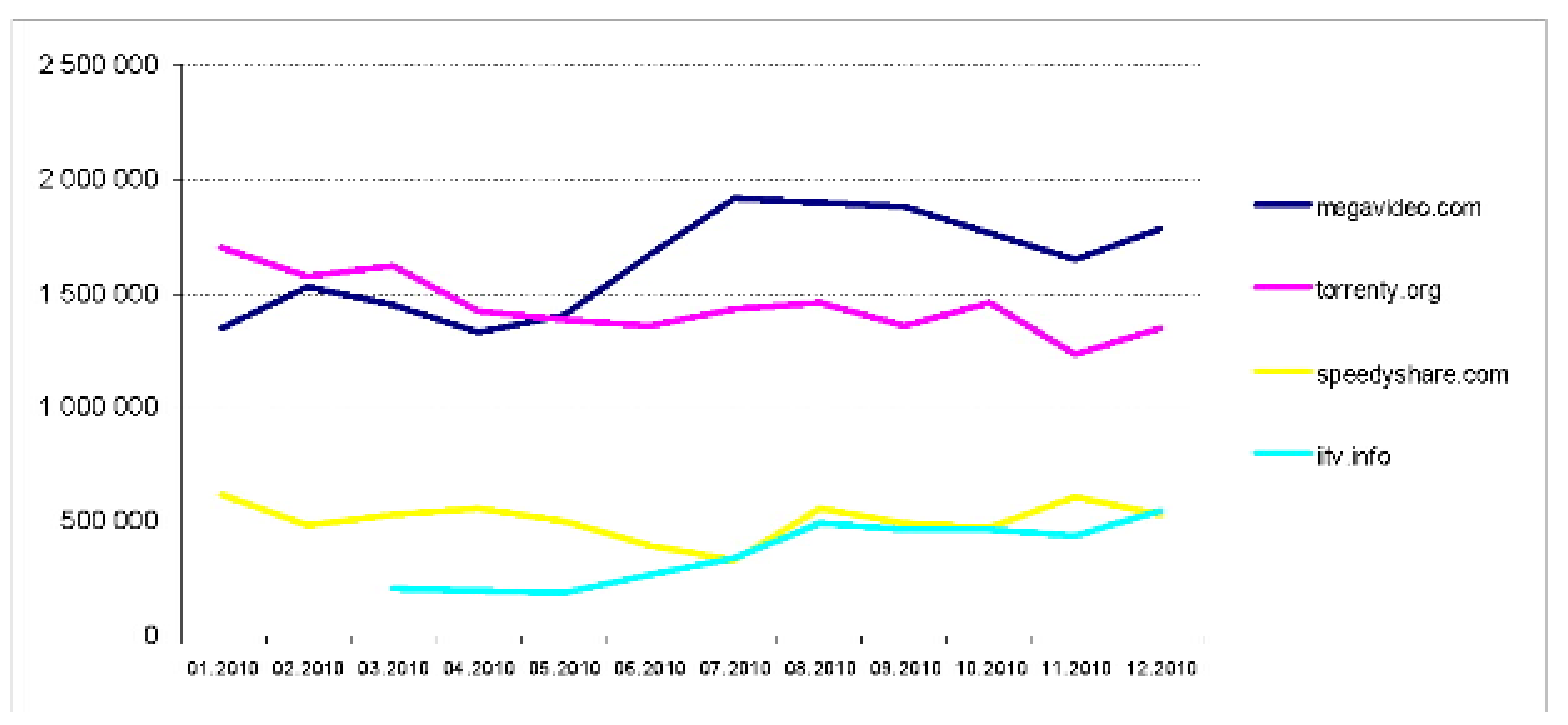

Another chart (Figure 2) shows the age structure of IiTV.info "real users" - whose number grew rapidly - that sustained over months. It is evident that the films accessible through this site were watched mainly by young people, aged 15-34.

Figure 2. Dynamics of age structure of IiTV.info "real users" in 2010. Source: Megapanel PBI/Gemius

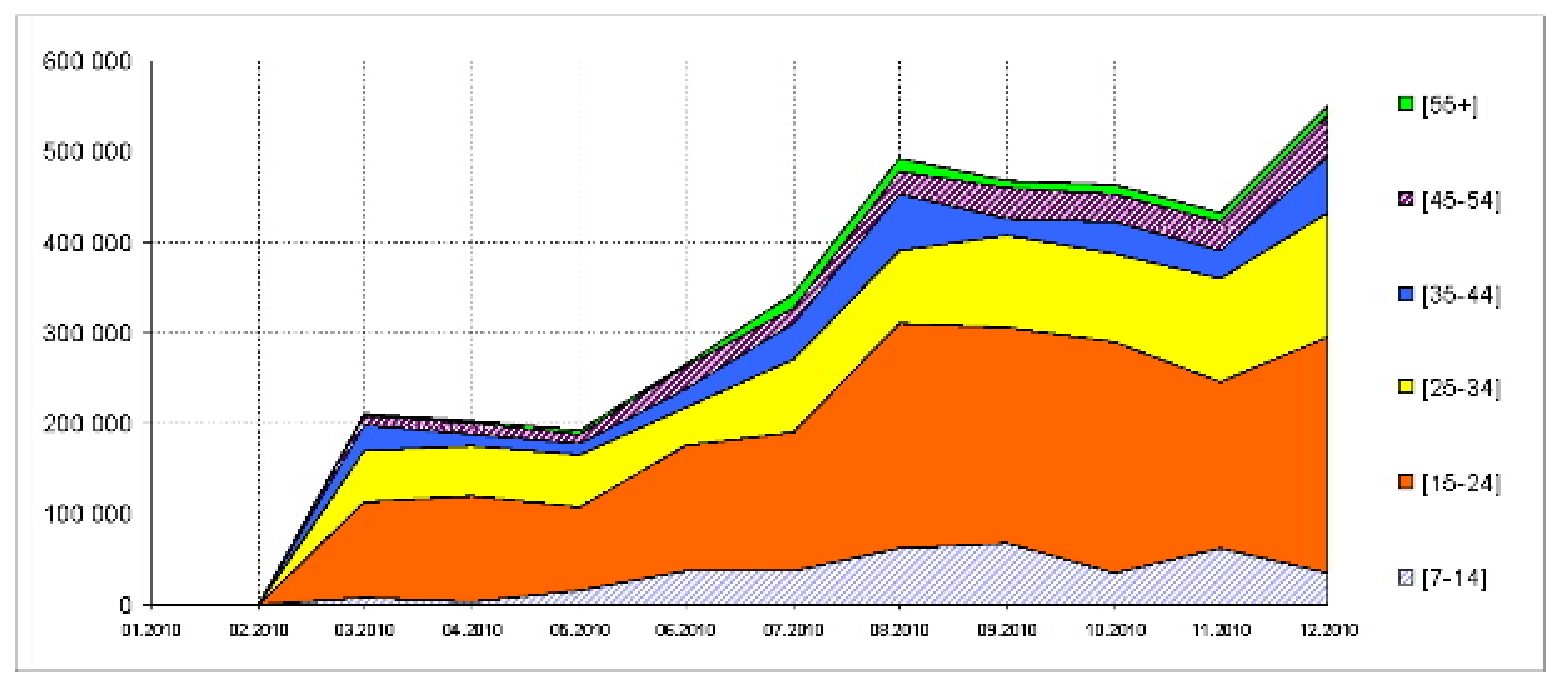

Other available sources of knowledge concerning the audience of specific websites such as Google AdPlanner or Alexa, although even more anecdotal from the methodological 
viewpoint, also confirmed the global popularity of sites that do not have the rights to broadcast their content in Poland. Additionally, they help to situate this knowledge in comparison with other countries. Google Ad Planner is obviously an imperfect website ranking, because its methodology is not entirely clear. For example, a domain with pop-up surveys which is not a website at all is listed there among the most popular Polish websites (it ranked $17^{\text {th }}$ in December 2010). Among the top hundred sites most often visited by Polish Internet users were listed such websites as Sciaga.pl with ready school essays and homework materials or sites linking mainly to movie files and music, e.g., Torrenty.org (http://www.google.com/adplanner/static/top100countries/pl.html). It is hard to find similar sites in the ranking of the top U.S. sites (http://www.google.com/adplanner/static/top100countries/us.html). According to Google AdPlanner, Megavideo.com ranked $37^{\text {th }}$ among the hundred most visited sites in the ranking of Italian Internet users (http://www.google.com/adplanner/static/top100countries/it.html) and $87^{\text {th }}$ in the ranking of French Internet users (http://www.google.com/adplanner/static/top100countries/fr.html).

The positions of two of the above sites in various markets are presented in Figure 3, which shows differences in the popularity of the sites depending on the country. The data, unless otherwise indicated, come from Alexa.com, which means that they are based mainly on the measurement of traffic from web browsers on the computers of people who installed the toolbar. The sample is then skewed in the direction of those users who demonstrate a specific pattern of use and this methodology can easily be undermined. However, the table may still serve as an illustration of the phenomena being discussed.

Figure 3. Megavideo.com and IiTV.info websites positions in audience rankings by Alexa.com and Google AdPlanner (as of March 2011)

\begin{tabular}{|l|l|}
\hline $\begin{array}{l}\text { Megavideo.com Worldwide Traffic } \\
\text { Rank } \\
\text { (bttp:/ / wmw.alexa.com/ siteinfo/m } \\
\text { egavideo.com) }\end{array}$ & \\
\hline Italy & 18 (37 according to Google AdPlanner) \\
\hline Spain & 19 \\
\hline Mexico & 32 \\
\hline Peru & 33 \\
\hline
\end{tabular}


Filiciak, Toczyski/Studia z Etyki i Edukacji Globalnej/ nr 1/2014, ss. 117-135

\begin{tabular}{|c|c|}
\hline France & 36 (87 according to Google AdPlanner) \\
\hline Belgium & 37 \\
\hline Argentina & 42 \\
\hline Colombia & 42 \\
\hline Israel & 45 \\
\hline Switzerland & 47 \\
\hline Chile & 49 \\
\hline Venezuela & 51 \\
\hline Japan & 66 \\
\hline Brazil & 76 \\
\hline Poland & 77 \\
\hline Canada & 79 \\
\hline Pakistan & 90 \\
\hline Algeria & 100 \\
\hline United Kingdom & 149 \\
\hline Australia & 180 \\
\hline India & 220 \\
\hline Germany & 245 \\
\hline United States & 253 \\
\hline South Korea & 264 \\
\hline Turkey & 268 \\
\hline Netherlands & 286 \\
\hline $\begin{array}{l}\text { IiTV.info Worldwide } \\
\text { Rank } \\
\text { (bttp:/ / www.alexa.ce } \\
\text { TV.info) }\end{array}$ & \\
\hline Poland & 107 \\
\hline Ireland & 4,112 \\
\hline United Kingdom & 19,538 \\
\hline Germany & 47,546 \\
\hline
\end{tabular}

Figure 3 shows that according to Alexa.com data, Megavideo was $77^{\text {th }}$ among the sites visited by Polish Internet users. The local IiTV.info website, based on the pieces of content 
aggregated in Megavideo, which are shown in a structured and indexed way, most often with Polish subtitles, reached especially the Poles using the Internet on the Polish territory (107 position). Abroad, it probably reached Poles working there (very low positions in the rankings relating to three European countries with large numbers of Polish immigrants).

\section{Research Results 2. Free AcCess: The Opinions and DeClarations of Polish INTERNET USERS}

We want to point out some issues from a pilot study preceding the above analysis and the IiTV.info growth. The study was carried out in the first half of February 2009 with the computerassisted web interviews (CAWI) method. This topic was broadened as part of the project under the working title "TV Series," later named "TV without TV sets?" by us. The purpose of this study was an attempt to capture a wide sample of TV series viewers and assess initially various ways of TV series consumption. The survey link was sent to the users of one of the top Polish horizontal portals by e-mail (the title of which was 'Do you like series? Don't you like series? Tell us about it"). The resulting sample was non-random, consisting of 1303 completed surveys, of which 1206 were filled out by series viewers. The main research question was whether television without TV sets, based on accessing successive episodes online, is becoming an important way to access TV productions in Poland in the first decade of the $21^{\text {st }}$ century.

The survey results confirmed the changing pattern of cultural content consumption by Internet users. The study itself was conducted to provide an overview for the national scientific conference "The new generation of television series and the Polish audience" (12-13 March 2009). The sample was consistent in terms of size of place of residence with the profile of Polish Internet users in the research named "NetTrack", which enriched the data on IiTV.info we got from our main source, i.e. Megapanel PBI/Gemius, but was not consistent with that study in terms of age structure. Therefore, the conclusions cannot be generalized to the whole population of Polish Internet users. The survey was intended to initiate a reflection on the contemporary ways of participation in culture, previously absent in the broad mainstream of Polish humanities. As younger Internet users (who were an under-represented age group in our study) download content from the Web more often than others do, the actual number of people who download files may be larger than in our study.

The results showed that 80 percent of the respondents watched series on television according to the TV guide, whereas any of online ways of accessing content was declared by 39 percent of all the respondents. The ways of accessing pieces of content via the Internet were: watching a series from a file downloaded personally from the Internet (26\%), from 
a received/borrowed CD or DVD with episodes downloaded from the Internet (16\%), and watching a series online using websites which provide streaming services (11\%).

Some results indicate highly local properties of series consumption: the most popular Polish TV series was chosen by almost twice as many respondents as the most popular foreign series. The high number of viewers watching TV series on their own $(55 \%)$ suggests that the consumption of series has no longer the function typical for linear television, i.e. the function of a social ritual. The key was, however, the projective question. In the survey, we used questions directly asking about downloading, but being aware that many respondents may feel uncomfortable about them and, in consequence, might not be honest, we also asked: "Do your friends download TV series from the Web?" "No", replied 14 percent of the respondents.

It is particularly interesting as we know that this is a sensitive issue: we learned from the questions about watching TV series that 26 percent of the respondents watched television series downloaded from the Internet and we also know - from the open questions at the end of the survey - that the respondents declared their concerns about the anonymity of the survey (which is typical for respondents approached by e-mail). Therefore, the number of respondents accessing content without due diligence in terms of intellectual property rights was probably between 26 percent (those who declared watching TV series from the files downloaded by themselves) and 47 percent (those who pointed to their "friends" in the key question) of the total number of series viewers in our sample. In the group of people younger than 24 years of age, 66 percent of the respondents watched television series according to the TV guide and 87 percent watched them in some online-related ways. Watching the series was the respondents' daily or almost daily activity.

One-fifth of the series viewers described themselves as "TV series fans", and almost each fan would read an online message board for a given series. The fans' most frequent creative activities were entries on those message boards. In their answers to the open questions, the respondents emphasized the lack of advertisements and the voice-over (a common alternative to subtitles on Polish television) as well as the possibility to control the time of viewing. Their expectation of control was revealed in the frequent repetitions of the words "I want" in their open statements. Many respondents stressed that they wanted to watch the episodes immediately after their release on American television.

\section{CONCLUSIONS}

We are aware that the issues presented above should be further studied through an even more detailed historical analysis and fully conclusive quantitative surveys should be conducted on 
a random sample and followed by qualitative research deepening our understanding of the issues. But even this research, which is not the best in terms of data quality, has touched upon two issues, in which the problem of "piracy" is situated, and has led us to some conclusions.

The first issue is the old "center" and "periphery" of global media flow processes and their relationship with the current legal standards. The second issue are the tensions between the dominant and non-dominant discourses in the academic way of describing changes in the media as an increase in Internet users' creative activities. The real - not so creative - use of the Polish Web points to "peer re-production" and leads to re-imagining the culture industry as an "extended culture industry" that is linked to global transfers of media content. We presented data on the mass scale of this phenomenon. Some other data, both from desk research and our own survey among Polish Internet users, validated these figures. It turns out that sharing American television series on the Polish Internet is a mass phenomenon, especially among young people. This confirms the generational determinants of "peer re-production." As demonstrated above, the extent of Polish "piracy" centered around television content already in 2009-2010. It involved a substantial part of society and in the case of young people it was a big part of this age group. It is clear that the ethical judgment of these practices is absolutely not part of the cultivated topdown criticism of "piracy" for a large number of Internet users.

This leads to the conclusion that conceptualizing access to audiovisual content primarily as access mediated through legal channels of content distribution makes a huge part of the cultural experience of Polish Internet users disappear from the field of vision. It is hard to even call them a "gray area" because in terms of both the scale and the perceived quality, it is a phenomenon that is already competitive with the traditional model.

It is no longer a margin, but a new mainstream of culture, against which the legal restrictions turn out to be surprisingly vulnerable. Unlike legislators, however, we are in a more comfortable situation as researchers - "piracy" in the online edition opens a new and intriguing area of reflection for us in which the content is not only commodities; attached to the exchange of messages, it turns from products into free tokens circulating in the social networks of the network society.

It is symbolic that television - until recently the iconic national medium, operating in a centralized model of broadcasting - is subject to this change. Today, pieces of television content circulate in informal networks, bypassing the law and national boundaries, and are surprisingly effective in meeting the needs of Internet users. Abigail de Kosnik, analyzing the content of television "piracy," suggests that if customers want to have access to them through a single interface and expect a format that will work on any programming platform, and also 
expect that content can be transferred freely between devices, then (...) such customers are condemned to pirated content. Perhaps, as it often happened in the past, "legal services can model their protocols directly on established pirate standards, as they are hardly secret" (de Kosnik 2011: 13).

It should be noted, however, that while some of our comments relate primarily to $\mathrm{p} 2 \mathrm{p}$ file-sharing networks, there is also a clear trend towards professional (although still illegal) intermediaries offering customers more convenient free (although usually ad-supported) access through streaming services. So perhaps Internet "piracy" is not a step towards the autonomy of consumers, but only a transition period towards the establishment of new models of mediation in access to content? This question is difficult to answer today. However, it appears that Internet users being participants of peer re-production will become part of the culture industries on a permanent basis.

\section{ACKNOWLEDGEMENTS}

Authors would like to thank all who contributed to our understanding of the above mentioned dilemmas and paradoxical phenomena. We would also like to express our special gratitude to the Polish Internet Research (PBI.org.pl) for enabling us to analyze Polish online audience data which are the market standard in this country.

\section{REFERENCES}

All online links valid as of June 16, 2014

Benkler, Y. (2006). Wealth of the Networks. How Social Production Transforms Markets and Freedom. New Haven and London: Yale University Press.

Ernesto (2008). 50\% of All BitTorrent Downloads are TV-Shows. Retrieved from http://torrentfreak.com/50-percent-bittorrent-downloads-TV-080214

Filiciak, M., et al. (2013). Youth and Media. Frankfurt: Peter Lang.

Filiciak, M., Hofmokl, J., Tarkowski, A. (2012). The Circulations of Culture. On Social Distribution of Content. Research report, September 2012. Warsaw: Digital Centre at Project: Poland. Retrieved from http://obiegikultury.centrumcyfrowe.pl/the_circulations_of_culture_report.pdf 
Jenkins, H., Li, X., Krauskopf, A. D. \& Green, J. (2010). If It Doesn't Spread, It's Dead. Creating $V$ alue in a Spreadable Marketplace. Retrieved from http://convergenceculture.org/research/Spreadability doublesidedprint final 063009.pdf

Karaganis, J. (Ed.). (2011a). Media Piracy in Emerging Economies. Retrieved from http://piracy.ssrc.org/the-report/

Karaganis, J. (2011b). The Consumer's Dilemma. Retrieved from http://piracy.ssrc.org/theconsumers-dilemma/

de Kosnik, A. (2011). Piracy is the Future of Television. Retrieved from http://convergenceculture.org/research/c3-piracy_future television-full.pdf

Krastev, I., Żakowski, J. (2011). Julian bez ziemi. Rozmowa o epoce po Wikileaks, histerii elit i zbliżającym się dyktacie emerytów. Polityka. Retrieved from

http://www.polityka.pl/swiat/rozmowy/1511790,1,rozmowa-z-ivanem-krastevem-filozofem-ipolitologiem.read

Kuczyński, P. (2014). Potencjał ruchu społecznego. In: Ł. Jurczyszyn, J. Kołtan, P. Kuczyński, M. Rakusa-Suszczewski (eds.). Obywatele ACTA. Gdańsk: Europejskie Centrum Solidarności.

Larkin, B. (2004). Degraded Images, Distorted Sounds: Nigerian Video and the

Infrastructure of Piracy. Public Culture, 16(2), 289-314.

Lessig, L. (2004). Free Culture: How Big Media Uses Technology and the Law to Lock Down Culture and Control Creativity. New York: The Penguin.

Lobato, R. (2010). Creative industries and informal economies: Lessons from Nollywood. International Journal of Cultural Studies, July 2010, 13, 337-354.

Logie, J. (2006). Peers, Pirates and Persuasion. Rhetoric in the Peer-to-Peer Debates. West Lafayette, Indiana: Parlor Press.

Roettgers, J. (2011). Piracy: Everybody Does It; Everything Should Be Free, New York Times. Retrieved from http://www.nytimes.com/external/gigaom/2011/02/16/16gigaom-piracyeverybody-does-it-everything-should-be-fre-88982.html

Schaefer, M. T. (2009). Participation Inside? User Activities between Design and Appropriation. In M. van den Boomen, S. Lammes, A.-S. Lehmann, J. Raessens \& M. T. Schaefer. Digital Material. Tracing New Media in Everday Life and Technology (147-158.). Amsterdam: Amsterdam University Press.

Terranova, T. (2000), Free Labor: Producing Culture for the Digital Economy. Social Text, 63, Vol. 18, No. 2, 33-58.

Toczyski, P. (2012). Active Internet users - a perspective on managing the experience. [in:] M. Filiciak, J. Hofmokl, A. Tarkowski: The Circulations of Culture. On Social Distribution of Content. Research report, September 2012. Warsaw: Digital Centre at Project: Poland. 97-103. Retrieved from https://depot.ceon.pl/bitstream/handle/123456789/3633/2012-Toczyski-Active-Internet-usersa-perspective-on-managing.pdf

Toczyski, P. (2013). Jak mit jednoczy Europe? Analiza arturiańskich elementów kultury symbolicznej jako csynników jednoczacych wspótczesna Europe. Warszawa: Collegium Civitas Press.

Weijters, B., Goedertier, F., Verstreken, S. (2014, forthcoming). Online Music Consumption in Today's Technological Context: Putting the Influence of Ethics in Perspective. Journal of Business Ethics. 